\title{
Remote Sensing Monitoring Shows that Climate Change has a Significant Impact on Vegetation Ecosystem in Central Asia
}

\author{
Ping Liü ${ }^{1,2}$, Xi Chen 1, 2,3*, Chi Zhang ${ }^{1,2,3}$ and Geping Luo ${ }^{1,2,3}$ \\ ${ }^{1}$ State Key Laboratory of Desert and Oasis Ecology, Xinjiang Institute of Ecology and Geography, Chinese Academy of Sciences, China \\ ${ }^{2}$ University of Chinese Academy of Sciences, China \\ ${ }^{3}$ Research Center of Ecology and Environment in Central Asia, Chinese Academy of Sciences, China
}

Submission: January 31, 2019; Published: February 15, 2019

*Corresponding author: Xi Chen, State Key Laboratory of Desert and Oasis Ecology, Xinjiang Institute of Ecology and Geography, Chinese Academy of Sciences \& Research Center of Ecology and Environment in Central Asia, Urumqi 830011, China

Abstract

The arid regions of Central Asia are one of the most representative arid regions in the northern mid-latitudes, which includes Kazakhstan, Uzbekistan, Kyrgyzstan, Turkmenistan, Tajikistan and Xinjiang in China, with a total area of 6 million km2, more than 80\% of the world's temperate deserts are located and has formed a unique temperate desert landscape pattern. Studies have shown that in the past three decades, the temperature in Central Asia rises by $0.4^{\circ} \mathrm{C}$ per decade, which is significantly higher than the average of the northern hemisphere and surrounding areas $\left(0.3^{\circ} \mathrm{C} / 10 \mathrm{a}\right)$. During the end 30 years in the late 20th century, severe drought occurred in the northwestern region of Central Asia, while precipitation in Xinjiang in the eastern part of Central Asia increased significantly. The precipitation in this region showed strong spatial heterogeneity and significant chronological fluctuations. The dramatic and complex climate change pattern has led to a complex response to Central Asian vegetation ecosystem productivity and carbon processes. These effects caused widespread concern in different areas, and in the past few years, some research have used remote sensing technology to study the climate and vegetation ecosystem of the region from different perspectives. Therefore, this mini review aims to link these studies to provide a comprehensive understanding of the relationship between climate change and ecosystem of Central Asia.

Keywords: Central asia; Climate change; Vegetation ecosystem; Net primary productivity

Abbreviations: TOTC: Total Organic Carbon Pool; VEGC: Vegetation Carbon Pool; SOC: Soil Organic Carbon Pool; LTRC: Litter Carbon Pool; NDVI: Normalized Difference Vegetation Index

\section{Introduction}

The effects of climate change and human activities on the Earth's systems, surface landscapes, and biogeochemical cycles are dramatically changing the response and adaptation mechanisms of the global ecosystem. Climate warming, abnormal precipitation, and a surge in greenhouse gas concentrations are a serious threat to the sustainable development of terrestrial ecosystems and human societies [1]. The carbon cycle is a key process in the biogeochemical cycle. And Carbon Sequestration is an important function of the ecosystem. Since the industrial revolution, especially from 1950s, human activities have greatly accelerated the variation and uncertainty of global change. Climate change and environmental issues are becoming more prominent. Terrestrial ecosystems bear the brunt of the threat of environmental degradation due to their role in the global carbon cycle, coupled with their sensitive environmental adaptation mechanisms and complex feedback mechanisms. Therefore, a correct and comprehensive understanding of the carbon cycle of terrestrial ecosystems is an important guarantee for predicting the impact of future climate change on human society and maintaining the sustainable development of ecosystems. The Central Asia Arid Zone is one of the most representative arid regions in the mid-latitudes of the Northern Hemisphere with a unique temperate desert ecosystem in the world. The arid regions of Central Asia (Figure 1) mainly include the five Central Asian countries (CAS: Kazakhstan, Uzbekistan, Kyrgyzstan, Turkmenistan and Tajikistan) and Xinjiang in China, with a total area of 6 million square kilometers.

More than $80 \%$ of the world's temperate deserts are located and has formed a unique temperate desert landscape pattern [2]. In the past 30 years, the global warming trend has intensified, the $\mathrm{CO}_{\mathrm{s}}$ concentration has risen to $398.55 \mathrm{ppm}$, and the average annual growth rate of $2.11 \mathrm{ppm}$ in the past ten years (2005 2014) is twice that of 1960s, the large increase in greenhouse gases has pushed the temperature rise beyond 
expectations, which is more pronounced in arid ecosystems. Studies have shown that in the past three decades, the heating rate in Central Asia has reached $0.4^{\circ} \mathrm{C} / 10 \mathrm{a}$, which is significantly higher than that in the northern hemisphere $\left(0.3^{\circ} \mathrm{C} / 10 \mathrm{a}\right)$ and surrounding areas [3]. During the end 30 years in the late 20th century, severe drought occurred in the northwestern region of Central Asia, while precipitation in Xinjiang in the eastern part of Central Asia increased significantly. The precipitation in this region showed strong spatial heterogeneity and significant chronological fluctuations [4]. The dramatic and complex climate change pattern has led to a complex response to Central Asian ecosystem productivity and carbon processes. This mini review focuses on the spatiotemporal patterns of ecosystem productivity and carbon dynamics in the past three decades to study the response mechanism of vegetation ecology to climate change in this area.

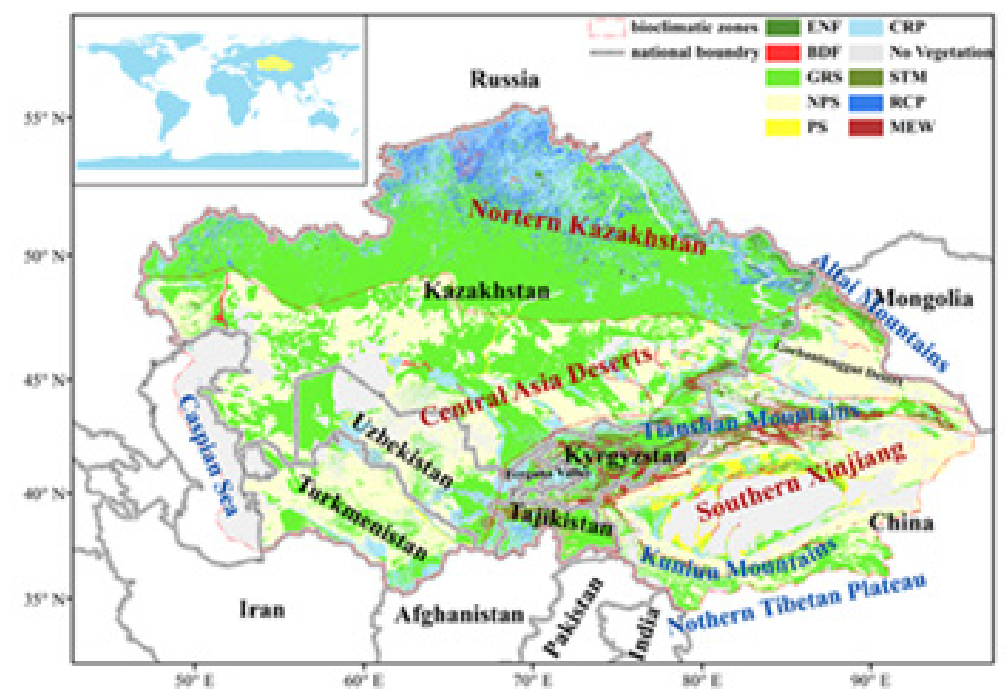

Figure 1: Geographical location of Central Asia [3].

\section{Temperature and Precipitation Changes}

During the 30 years from 1979 to 2011, temperatures in Central Asia increased significantly, while precipitation reduced sharply. As shown in Figure 2(a), the average temperature rose by 0.4 degrees per decade and the annual precipitation dropped by $5.8 \mathrm{~mm}$. Moreover, a drought that lasted for ten years from 1998 to 2008. The precipitation during the period was only $80 \%$ of the average value (1979-2011). At the same time, the annual average temperature reached $5.62{ }^{\circ} \mathrm{C}$, higher than the 30 -year average temperature [3]. To illustrate the spatial pattern of climate change, $\mathrm{Li}$ et al. [2] calculated the temperature and precipitation distribution map for each simulated pixel from 1979 to 2011, as shown in Figure 2 (b) \& (c). The results show that the Gurbantunggut Desert in southeastern Xinjiang and northern Xinjiang is warming strongly, with an average annual variation greater than $0.06{ }^{\circ} \mathrm{C}$, and precipitation in northern Xinjiang is significantly reduced. Precipitation in Kazakhstan, Kyrgyzstan and southwestern Xinjiang has been severely reduced, while precipitation has increased in northern and southeastern Xinjiang.

Studies have shown that the severe drought in Central Asia may be caused by the oceanic sources related to the cold phases of the El Niño-Southern Oscillation (ENSO) [5,6]. According to climate simulation studies, the La Niña event that has continued in recent decades is due to the significant warming of the Indian
Ocean and the western Pacific Ocean, which enhances the regional contrast of sea surface temperatures in the tropical Pacific Ocean [7]. In order to express this effect more intuitively, La Niña's record [8] is added in Figure 2(a). This abnormal warming is partly due to the response of the ocean to increased greenhouse gases in the atmosphere $[9,10]$. With climate warming [1], the frequency and intensity of ENSO is growing [11], and the resulting drought will continue to jeopardize the ecosystems of Central Asia.

\section{Net Primary Productivity of Ecosystems Changes}

Since the majority of the geographical coverage of Central Asia, it is including different vegetation, soil and climate patterns. Moreover, there is heterogeneity over a span of thirty years and therefore cannot be measured directly on a regional scale [12]. Because of the vast geographic coverage of Central Asia, it includes different vegetation, soil and climate models. Moreover, there is heterogeneity over a span of thirty years and therefore cannot be measured directly on a regional scale [13]. Ecosystembased modeling can analyze complex ecosystem processes and potential internal linkages and has proven to be a powerful tool for analyzing environmental factors [14-16]. However, common models such as Biome-BGC [17], CENTURY [18], OCHIDEE [19], etc., lack analysis of vegetation structure and ecological physiological processes in arid regions. Therefore, it cannot be used for analysis in this area $[20,21]$. 
(a)
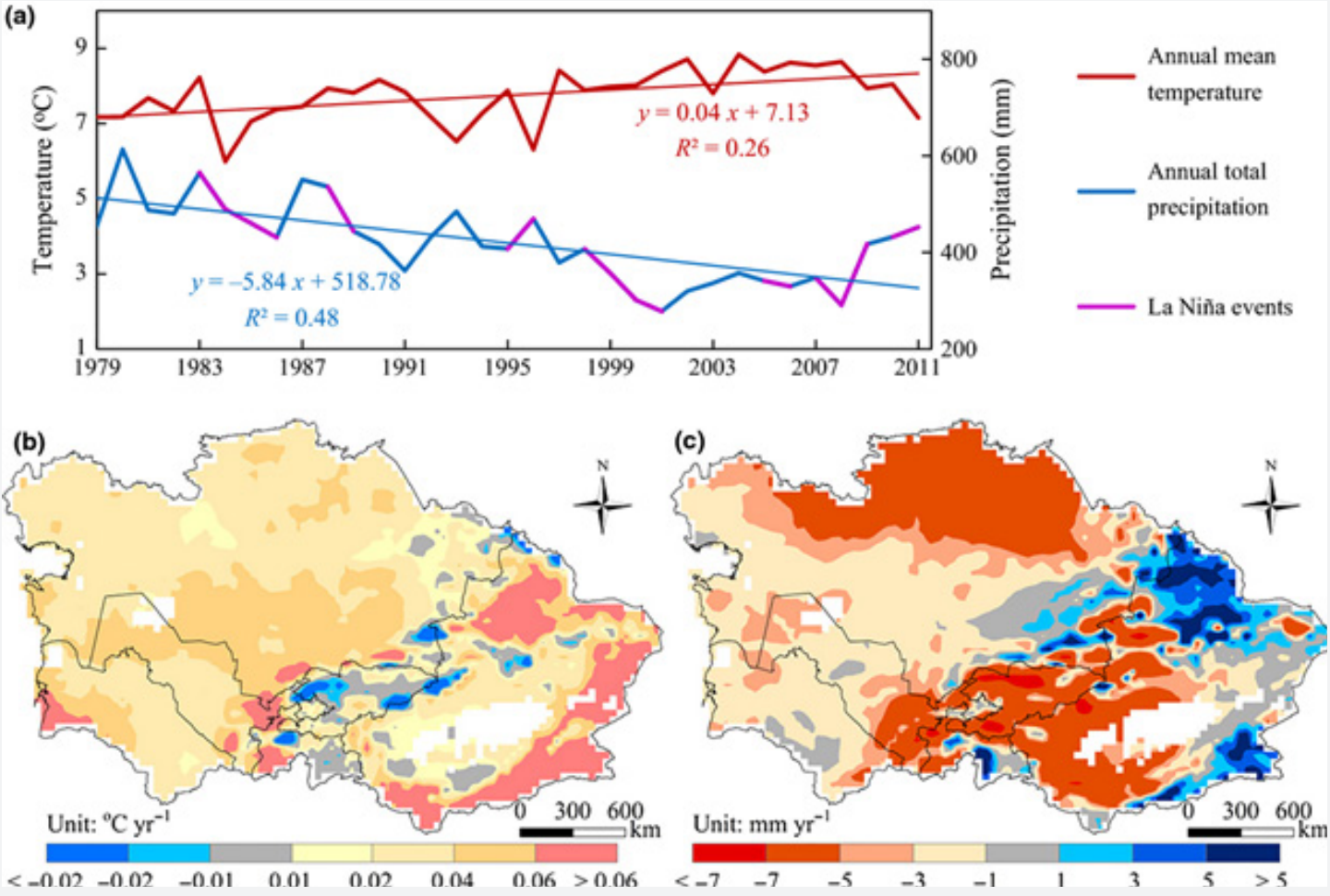

Figure 2: Spatial and temporal changes in temperature and precipitation in Central Asia from 1979 to 2011 [2].

(a) Temporal changes in annual temperature and precipitation;

(b) spatial pattern of the temperature trend in 1979-2011;

(c) spatial pattern of the precipitation trend in 1979-2011.

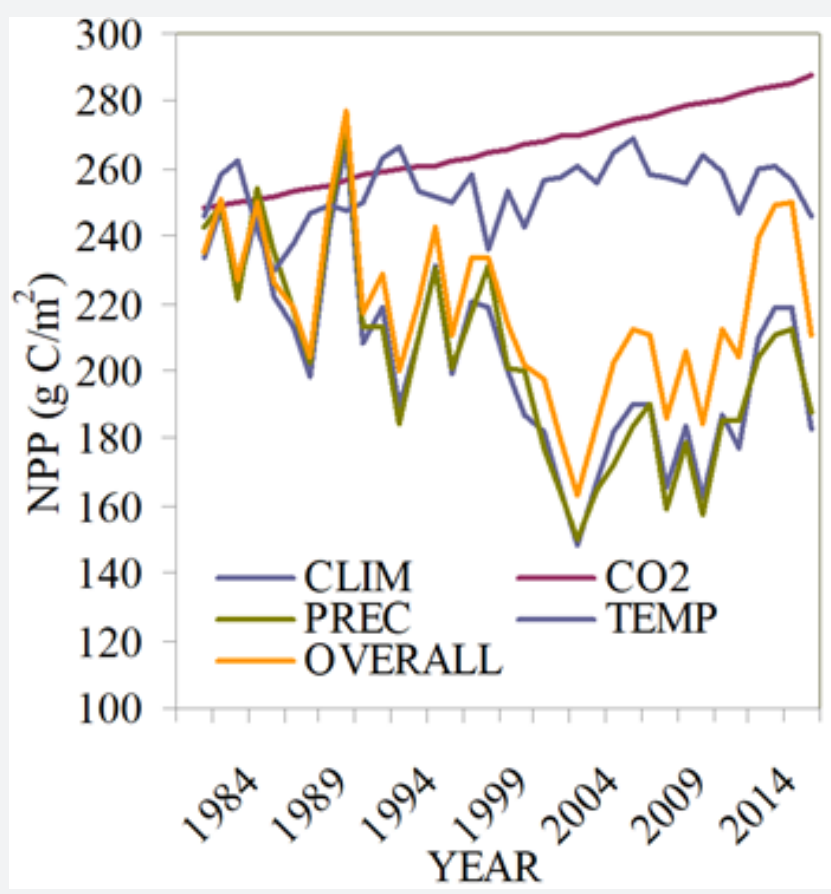

Figure 3: Variation of the NPP in Central Asia from 1980 to 2014 [13].

Zhang \& Ren $[15,16]$ first verified the arid ecosystem model (AEM) of the arid zone ecological model using field observation data, and evaluated the spatial and temporal patterns of NPP responses to climate and carbon dioxide changes in Central Asia from 1980 to 2014, and evaluated different environmental factors (precipitation, The relative contribution rate of temperature, 
C02) and its interaction effect, the results show that the average annual average NPP in the arid regions of Central Asia in the past 35 years is $218 \pm 25 \mathrm{~g} \mathrm{C} / \mathrm{m}^{2}$ [22], as shown in Figure 3. The annual NPP value is higher in the northern part of Kazakhstan $\left(349 \pm 39 \mathrm{~g} \mathrm{C} / \mathrm{m}^{2}\right)$, while the NPP value in southern Xinjiang is lower $\left(123 \pm 45 \mathrm{~g} \mathrm{C} / \mathrm{m}^{2}\right)$. The NPP value of temperate coniferous forest was the highest $\left(556 \pm 82 \mathrm{~g} \mathrm{C} / \mathrm{m}^{2}\right)$, and the non-deep root shrub had the lowest NPP value $\left(158 \pm 25 \mathrm{~g} \mathrm{C} / \mathrm{m}^{2}\right)$. From 1980 to 2014, NPP in Central Asia was decreasing by an average of $0.71 \mathrm{~g} \mathrm{C} / \mathrm{m}^{2}$ per year, and the NPP in the extreme arid region of southern Xinjiang was the most significant $\left(-2.05 \mathrm{~g} \mathrm{C} / \mathrm{m}^{2}\right)$, as shown in Figure 4 [2].

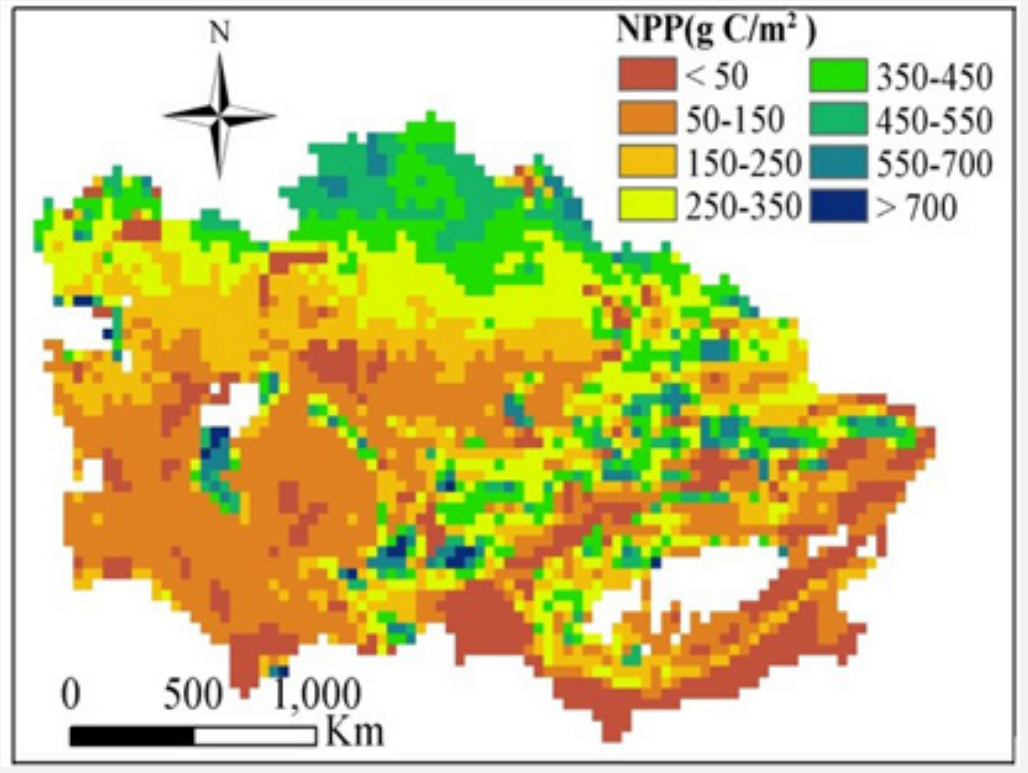

Figure 4: The spatial distribution of NPP in Central Asia from 1980 to 2014 [23].

Compared with the NPP mean value from 1980 to 1984 , the total NPP in the Central Asian region decreased by $118 \mathrm{Tg}$ or $-10 \%$ between 1985 and 2014. The $\mathrm{CO}_{2}$ fertilization effect promoted the increase of NPP by $99.7 \mathrm{Tg}$ or $+8 \%$ [2]. The positive effect of temperature increase promoted the increase of NPP by $35.4 \mathrm{Tg}$ or $+2 \%$, while the decrease of precipitation caused the NPP to decrease by $221 \mathrm{Tg}$ or $-18 \%$ [2]. The main controlling factor of NPP in $9 \%$ of the study area is temperature, which is mainly distributed in high-latitude alpine regions such as Tianshan and northern Kazakhstan. The main area of precipitation accounts for $69 \%$ of the entire study area, mainly distributed in desert plains, especially in southern Xinjiang. The $\mathrm{CO}_{2}$ main control area accounts for $20 \%$ of the study area and is mainly distributed in areas with good hydrothermal conditions such as forest areas and low-altitude areas in the Tianshan Mountains. The results show that southern Xinjiang is an important area of ecological fragility in Central Asia, and its ecological security faces the challenge of climate change.

\section{Vegetation and Soil Carbon Pools Changes}

Many studies have shown that the dynamics of the global carbon cycle are not only affected by human activities, but also closely related to the response of ecosystems to environmental changes. Arid ecosystems are extremely sensitive to climate change and human activities and are undergoing dramatic changes [24]. Ecological processes and their response and adaptation mechanisms are at the forefront of global change and ecological research in arid regions [25]. The total organic carbon pool (TOTC) of ecosystems mainly includes vegetation carbon pool (VEGC), soil organic carbon pool (SOC) and litter carbon pool (LTRC) [26]. Its temporal and spatial dynamics is the most intuitive performance of regional carbon source/sink pattern [2,27] used the 1979 carbon stocks as a benchmark to determine the relative changes in the ecosystem's carbon pools from 1980 to 2011. Negative values represent a reduction in the carbon pool for the corresponding year compared to 1979, which is represented by a carbon source; otherwise, a carbon sink. As shown in Figure 5, from 1979 to 2011, the region lost about $0.46 \mathrm{Pg} \mathrm{C}$, with an average annual loss of $0.02 \mathrm{Pg} \mathrm{C} / \mathrm{yr}$. It is worth noting that in 1979-1997, the ecosystem of Central Asia was almost a neutral state of carbon balance. The loss of carbon pool occurred mainly during the most severe drought in 19982008, of which 1998-2002 was the most significantly (-0.33Pg). After 2008, the carbon pool in Central Asia has rebounded with the increase of precipitation. Li et al. also found that the two most significant carbon loss phenomena in Central Asia occurred in 1998-2002 (-0.33Pg C) and 2005-2009 (-0.13Pg C) respectively [2]. These two time periods coincide with the time when the La Niña phenomenon occurs.

At the same time, Li et al. [2] also found that the reduction of TOTC in Central Asia was mainly caused by the loss of VEGC (Figure 5) [2]. During the period 1979-2011, VEGC showed significant attenuation under the influence of climate change, 
especially under the influence of precipitation reduction, with a total reduction of about $0.57 \mathrm{Pg} \mathrm{C}$, and the loss rate during the 1997-2002 period was as high as $0.09 \mathrm{Pg} \mathrm{C} / \mathrm{yr}(\mathrm{P}<0.001)$. This is mainly due to the continued low precipitation and rising temperatures, which exacerbates the inhibition of water productivity on vegetation [28], leading to a large number of vegetation [29]. The reduction of VEGC is an important indicator of regional vegetation degradation. The problem of ecological degradation caused by drought in Central Asia has been widely confirmed by domestic and foreign research [30-32] should be highly valued by local eco-managers and government decision makers. Unlike the decreasing trend of VEGC, the SOC in Central Asia increased steadily during the study period $(0.13 \mathrm{Pg} \mathrm{C}$ ). Moreover, its dynamic change was significantly negatively correlated with VEGC in time series $(r=-0.9, \mathrm{P}<0.001)$ (Figure 5). The fluctuation of the SOC is mainly determined by the balance between the input of litter carbon and the output of soil respiration. Studies have shown that soil moisture is the main environmental factor affecting soil respiration rate in arid ecosystems. The inhibition of soil stress caused by water stress caused by precipitation reduction is much greater than the positive effect of temperature increase [33]. This also explains the increase in SOC in Central Asia under the influence of reduced precipitation. In addition, although the litter carbon pool was higher than the stock in 1979 during most of the study period, its variation was extremely weak (Figure 5), and the contribution to the dynamics of the carbon stocks in the Central Asian region was not obvious.

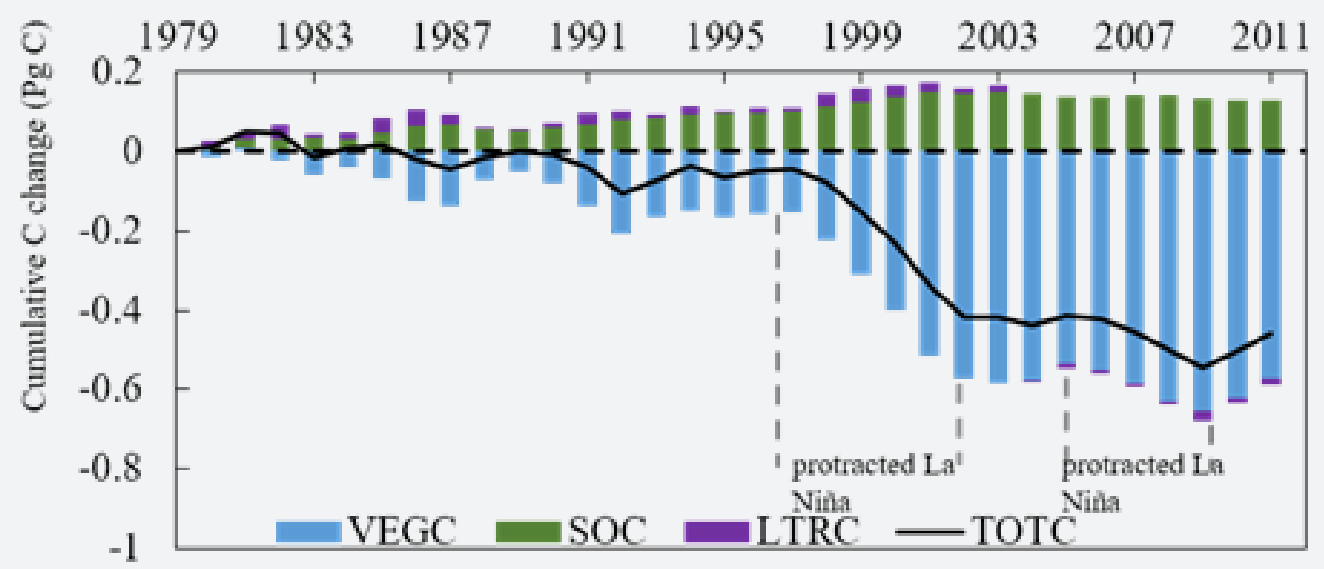

Figure 5: Variation of ecosystem carbon pool in Central Asia from 1979 to 2011.

In order to explore the spatial pattern of the carbon storage response of the Central Asian ecosystem to climate change, Li et al. [34] used the carbon pool difference between 2011 and 1979 as an indicator, and the positive value represented the increase of carbon pool during the study period [34]. As can be seen from Figure 6, the response of carbon stocks in different regions to climate change is significant. For example, the northern part of Kazakhstan was the region with the most degraded VEGC and SOC in Central Asia during the period 1979-2011. This finding is consistent with the results of several remote sensing studies showing that the normalized difference vegetation index (NDVI) in northern Kazakhstan has been severely degraded over the past 30 years. Northern region of Kazakhstan has become one of the most significant hotspots for vegetation browning in the world $[23,29,30,35]$. However, in the northern part of Xinjiang, although the former is in the same latitude zone, TOTC increased by $108 \mathrm{~g} \mathrm{C} \mathrm{m}^{-2}$ during the same period, and VEGC increased by $96 \mathrm{~g}$ $\mathrm{C} \mathrm{m}^{-2}$. It can be seen from Figure 2 that this change is consistent with the increase in precipitation in the region. During 19792011, the increase in precipitation in northern Xinjiang reduces the threat of drought and promotes plant growth in the region [34].

\section{Conclusion}

This mini review reviews vegetation productivity and ecosystem carbon dynamics response to climate change in arid regions of Central Asia over the past 30 years, with a focus on temporal and spatial response characteristics:

a) In the past three decades (from 1979-2011), the drought in Central Asia has been highly correlated with ENSO. With the current climate warming, the frequency and intensity of ENSO will increase, the ecosystem of Central Asia will face a more severe drought threat.

b) Increased temperature and precipitation tend to promote ecosystem photosynthesis and autotrophic respiration, thereby stimulating vegetation growth and ecosystem carbon flux; reduced precipitation will have the opposite effect of inhibiting ground NPP. However, in the arid regions of Central Asia, changes in NPP from 1980 to 2014 indicate that warming and drought have led to a downward trend in NPP (average annual reduction of $0.71 \mathrm{~g} \mathrm{C} / \mathrm{m}^{2}$ ), extremely dry areas in southern Xinjiang have changed significantly, with an average annual decline of $2.05 \mathrm{~g} \mathrm{C} /$ $\mathrm{m}^{2}$. Compared with the average NPP from 1980 to 1984 , the total amount of NPP in Central Asia decreased by $10 \%$ 
from 1985 to 2014 [36]. Therefore, with global warming, the temperature rises are unlikely to promote autotrophic respiration. The southern part of Xinjiang is the most vulnerable part of the ecology. As the temperature rises, its ecological sustainability will face greater challenges.

c) The two most significant carbon loss phenomena in Central Asia occurred in 1998-2002 (-0.33Pg C) and 2005-2009 (-0.13Pg C) coincided with the long-term La Nina event in the same period, if future climate warming
[1], the frequency and intensity of ENSO increase [11], the sustainability of dryland ecosystems of Central Asia will face more drought ecological crisis.

In addition, the two regions in Central Asia: northern Kazakhstan and Xinjiang, have similar geographic latitudes and vegetation cover types, but the climate change patterns are very different. In the future research, we can use this as an analysis case to conduct in-depth research on the interaction mechanism between dryland ecosystems.

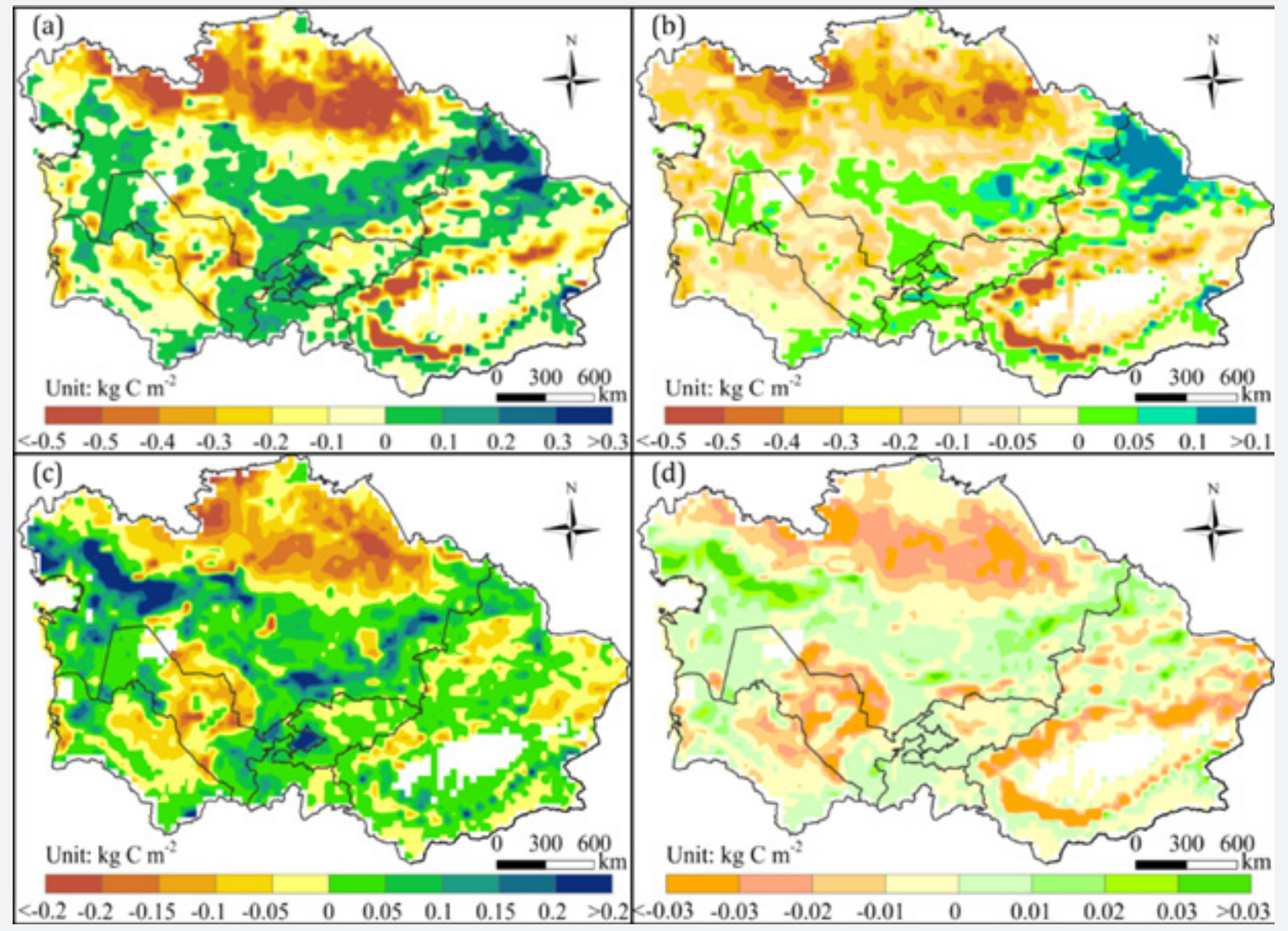

Figure 6: Changes in

(a) total ecosystem carbon density;

(b) vegetation carbon density;

(c) soil organic carbon density; and

(d) litter carbon density from 1979 to 2011 [2].

\section{Acknowledgements}

This research was supported by the Strategic Priority Research Program of Chinese Academy of Sciences (Grant No. XDA20060303), the International Cooperation Fund of Ecological Effects of Climate Change and Land Use/Cover Change in Arid and Semiarid Regions of Central Asia in the Most Recent 500 Years (Grant No. 41361140361).

\section{References}

1. AR5 Synthesis Report: Climate Change (2014) IPCC WGI Fifth Assessment Report.

2. Li C, Zhang C, Luo G, Chen X, Maisupova B (2015) Carbon stock and its responses to climate change in Central Asia. Global Change Biology 21(5): 1951-1967.
3. Hu Z, Zhang C, Hu Q Tian H (2014) Temperature Changes in Central Asia from 1979 to 2011 Based on Multiple Datasets. J Clim 27: 11431167.

4. Chen Xi ZC, Luo Geping (2014) Modeling dryland ecosystems' response to global change in Central Asia; China Meteorological Press, Beijing, China.

5. Barlow M, Cullen H, Lyon B (2002) Drought in Central and Southwest Asia: La Niña, the Warm Pool, and Indian Ocean Precipitation. Journal of Climate 15(7): 697-700.

6. Syed FS, Giorgi F, Pal JS, King MP (2006) Effect of remote forcings on the winter precipitation of central southwest Asia part 1: observations. Theoretical and Applied Climatology 86(1-4): 147-160.

7. Hoerling M, Kumar A (2003) The perfect ocean for drought. Science 299(5607): 691-694. 
8. El Niño and La Niña Years and Intensities.

9. Knutson TR, Manabe S (1998) Model assessment of decadal variability and trends in the tropical Pacific Ocean J Clim 11(9): 2273-2296.

10. Yeh SW, Kug JS, Dewitte B, Kwon MH, Kirtman BP (2009) Nino in a changing climate. Nature 461: 511-570.

11. Bastos A, Running SW, Gouveia C, Trigo RM (2013) The global NPP dependence on ENSO: La Nina and the extraordinary year of 2011. J Geophys Res Biogeosci 118(3): 1247-1255.

12. Fang JY, Piao SL, Field CB, Pan YD, Guo QH, et al. (2003) Increasing net primary production in China from 1982 to 1999. Front Ecol Environ 1: 293-297.

13. Li C, Luo G, Li J, Fan B, Han Q, et al. (2012) Net primary productivity and actual evapotranspiration of Central Asia in recent 20 years. Arid Land Geography 35: 919-927.

14. Ren W, Tian H, Tao B, Huang Y, Pan S (2012) China's crop productivity and soil carbon storage as influenced by multifactor global change. Global Change Biology 18(9): 2945-2957.

15. Zhang C, Tian H, Chappelka AH, Ren W, Chen H, et al. (2007) Impacts of climatic and atmospheric changes on carbon dynamics in the Great Smoky Mountains National Park. Environmental Pollution 149(3): 336-347.

16. Zhang C, Tian H, Chen G, Chappelka A, Xu X, et al. (2012) Impacts of urbanization on carbon balance in terrestrial ecosystems of the Southern United States. Environmental Pollution 164: 89-101.

17. Thorn AM, Xiao J, Ollinger SV (2015) Generalization and evaluation of the process-based forest ecosystem model PnET-CN for other biomes. Ecosphere 6(3): 1-27.

18. Parton WJ, Stewart JWB, Cole CV (1988) Dynamics of C, N, P and S in grassland soils: a model. Biogeochemistry 5(1): 109-131.

19. Krinner G, Viovy N, de Noblet-Ducoudre N, Ogee J, Polcher J, et al. (2005) A dynamic global vegetation model for studies of the coupled atmosphere-biosphere system. Global Biogeochemical Cycles 19(1).

20. Yang RQ, Friedl MA, Ni WG (2001) Parameterization of shortwave radiation fluxes for nonuniform vegetation canopies in land surface models. Journal of Geophysical Research-Atmospheres 106(D13): 1427514286.

21. Zeng X, Zeng X, Barlage M (2008) Growing temperate shrubs over arid and semiarid regions in the Community Land Model-Dynamic Global Vegetation Model. Global Biogeochemical Cycles 22(3).

22. Zhang C Ren W (2017) Complex climatic and $\mathrm{CO}_{2}$ controls on net primary productivity of temperate dryland ecosystems over central Asia during 1980-2014. J Geophys Res Biogeosci 122(9): 2356-2374.

23. Piao S, Ciais P, Lomas M, Beer C, Liu H, et al. (2011) Contribution of cli-

\section{This work is licensed under Creative}

Commons Attribution 4.0 License

Commons Attribution 4.0 License
DOI: $10.19080 /$ IJESNR.2019.17.555961 mate change and rising $\mathrm{CO}_{2}$ to terrestrial carbon balance in East Asia: A multi-model analysis. Global and Planetary Change 75(3-4): 133-142.

24. Chen X, Luo GP, Xia J, Zhou KF, Lou SP, et al. (2005) Ecological response to the climate change on the northern slope of the Tianshan Mountains in Xinjiang. Science in China Series D: Earth Sciences 48(6): 765-777.

25. Trumper K, Ravilious C, Dickson B (2008) Carbon in Drylands: Desertification, Climate Change and Carbon Finance. In Proceedings of In A UNEP-UNDP-UNCCD Technical Note for Discussions at CRIC 7 Istanbul, Turkey, pp. 03-14.

26. Xi Chen GL (2015) Carbon Cycle in Dryland Ecosystems of Central Asia; China Environmental Press, Beijing, China.

27. Ni J (2013) Carbon storage in Chinese terrestrial ecosystems: approaching a more accurate estimate. Climatic Change 119(3-4): 905917.

28. Piao S, Wang X, Ciais P, Zhu B, Wang T, et al. (2011) Changes in satellite-derived vegetation growth trend in temperate and boreal Eurasia from 1982 to 2006. Global Change Biology 17(10): 3228-3239.

29. Gessner U, Naeimi V, Klein I, Kuenzer C, Klein D, et al. (2013) The relationship between precipitation anomalies and satellite-derived vegetation activity in Central Asia. Global and Planetary Change 110: 74-87.

30. de Jong R, Verbesselt J, Schaepman ME, de Bruin S (2012) Trend changes in global greening and browning: contribution of short-term trends to longer-term change. Global Change Biology 18(2): 642-655.

31. Mohammat A, Wang X, Xu X, Peng L, Yang Y, et al. (2013) Drought and spring cooling induced recent decrease in vegetation growth in Inner Asia. Agricultural and Forest Meteorology 178-179: 21-30.

32. de Beurs KM, Henebry GM (2004) Land surface phenology, climatic variation, and institutional change: Analyzing agricultural land cover change in Kazakhstan. Remote Sensing of Environment 89(4): 497509.

33. Wu Z, Dijkstra P, Koch GW, Penuelas J, Hungate BA (2011) Responses of terrestrial ecosystems to temperature and precipitation change: a meta-analysis of experimental manipulation. Global Change Biology 17(2): 927-942.

34. Li CF, Zhang C, Luo GP, Chen X (2013) Modeling the carbon dynamics of the dryland ecosystems in Xinjiang, China from 1981 to 2007-The spatiotemporal patterns and climate controls. Ecol Model 267: 148-157.

35. de Beurs KM, Wright CK, Henebry GM (2009) Dual scale trend analysis for evaluating climatic and anthropogenic effects on the vegetated land surface in Russia and Kazakhstan. Environmental Research Letters $4(4)$.

36. Zhu S, Yan Y, Shao H, Li C (2017) The Responses of the Net Primary Productivity of the Dryland Ecosystems in Central Asia to the $\mathrm{CO}_{2}$ and Climate Changes during the Past 35 Years. Journal of Natural Resources 32(11): 1844-1856.

Your next submission with Juniper Publishers will reach you the below assets

- Quality Editorial service

- Swift Peer Review

- Reprints availability

- E-prints Service

- Manuscript Podcast for convenient understanding

- Global attainment for your research

- Manuscript accessibility in different formats

( Pdf, E-pub, Full Text, Audio)

- Unceasing customer service

Track the below URL for one-step submission https://juniperpublishers.com/online-submission.php 